\title{
MODA E FABRICAÇÃO DIGITAL EM UM CONTEXTO FAB LAB: EQUIPAMENTOS, MÉTODOS E PROCESSOS PARA O DESENVOLVIMENTO DE PRODUTOS.
}

\author{
Victoria Fernandez Bastos \\ Centro Universitário de João Pessoa \\ vickfb@gmail.com \\ Leonardo Castillo \\ Universidade Federal de Pernambuco \\ leonardo.castillo@ufpe.br
}

Resumo: A fabricação digital indica novos avanços tecnológicos que impactam diretamente no processo de design. Para alguns autores, estamos vivenciando a terceira revolução industrial, onde é possível conectar o universo virtual ao mundo real. Esta nova revolução implica em grandes mudanças no modo de pensar, criar, produzir e comercializar produtos, assim como novas formas de se relacionar com o mundo. Observando a trajetória da moda e o panorama atual, é perceptível a necessidade de desenvolver produtos cada vez mais inovadores tanto em termos estéticos como tecnológicos, além de rever métodos e processos, tanto no contexto de ateliês (produção mais artesanal e exclusiva) como da indústria (produção em grande escala). A prototipagem rápida e o surgimento de espaços alternativos, como a rede de Laboratórios de Fabricação Digital (FabLab), favorecem o compartilhamento de ideias, projetos e experiências e além disso fomentam movimentos que propõem uma direção alternativa à produção em série e à cultura de massa, apresentando possibilidades para uma produção mais exclusiva. Desta forma esta pesquisa se propõe a investigar como a moda pode usufruir das novas tecnologias, métodos e processos possíveis através da fabricação digital e do contexto Fab Lab.

Palavras-chave: design de moda, fabricação digital, projeto de produtos, processos de fabricação, fablab 


\section{INTRODUÇÃO}

O processo de industrialização trouxe muitos benefícios como a redução de custos de produção, melhor qualidade dos produtos e a uniformidade. Mas a massificação padronizou os produtos de forma que desconsidera as diferenças e as necessidades específicas de cada usuário. Por consequência, desperta no consumidor o desejo por produtos exclusivos ou customizados onde o usuário pode adaptar ou personalizar ou torná-los únicos.

A partir desse desejo e apoiados pela evolução tecnológica da fabricação digital, autores como Neil Gershenfeld (2005), Chris Anderson (2010) e Peter Troxler (2013) apontam para uma $3^{a}$ Revolução Industrial, que acompanha a evolução dos computadores pessoais desde a década de 50 até os dias atuais. Segundo os autores, esta revolução não vem para substituir o modelo de manufatura atual, mas tem capacidade de produzir bens materiais assim como as indústrias, porém utilizando informações de dados de computadores na materialização.

Ao refletirmos sobre o design e o designer nesse contexto, não ficam claros seus papeis em especial por se tratar de uma atividade que está sempre se reinventando e se adaptando às mudanças do mundo. Por exemplo, com o surgimento dos equipamentos e ferramentas de fabricação digital a preços acessíveis, conectados ao mundo pela internet, surgem novos paradigmas de produção que combinam produção digital com produção pessoal-tradicional. Nesse contexto,como o design de moda poderia se apropriar dos métodos, materiais e processos advindos desse novo paradigma para criar produtos com valor de moda?

O objetivo deste trabalho é evidenciar as possibilidades da fabricação digital para o desenvolvimento de produtos de moda. Para atingir o objetivo optou-se por uma abordagem qualitativa, por entender que, na situação atual, uma investigação que possibilite um levantamento de maior número de dados a fim de iniciar o aprofundamento da relação moda e fabricação digital. Para isso foram selecionadas técnicas de coleta de dados como: levantamento bibliográfico, questionário preliminar, pesquisa de campo e entrevistas semiestruturadas.

\section{O PARADIGMA DA FABRICAÇÃO DIGITAL}

Ao longo dos últimos 200 anos, três momentos marcaram a forma como foram definidos os processos de criação, produção e consumo de produtos (ABEL; et al., 2011 , p. 29). Num primeiro momento, durante a consolidação da primeira revolução industrial, surge a figura do designer/fabricante, do qual podemos fazer relação com o artesão do mesmo período que elabora a sua ideia. Na oficina ele desenvolve os produtos. O resultado são produtos variados que o consumidor adquire, sem participação no processo.

Já num segundo momento, dentro do contexto da segunda revolução industrial, um dos objetivos é produção e consumo em massa. Nesse contexto, o designer tem a ideia, a indústria fabrica produtos idênticos, massificados e o consumidor passivo consome.

Por fim, no terceiro momento, dentro do marco da chamada $3^{a}$ revolução industrial começa a se delinear uma nova perspectiva. Surgem mais protagonistas no processo de criação e consumo. O designer colaborador e o consumidor colaborador compartilham ideias, as colocam em um espaço virtual e interativo de co-designe open 
design. O produto é materializado a partir da fabricação digital e o consumidor final pode adquirir ou mesmo fabricar produtos personalizados.

Nesse novo panorama, o termo "fabricação digital" esta relacionado aos processos que utilizam ferramentas de produção controladas por computador. Porém, um significado mais profundo do termo faz referencia aos os "processos de fabricação em que os próprios materiais serão digitais". Uma série de laboratórios estádesenvolvendo materiais digitais para o futuro da fabricação (GERSHENFELD, 2012, p.50).

Hoje qualquer pessoa com acesso a internet, uma boa ideia e um pouco de conhecimento do processo pode produzir em pequena ou grande escala. Anderson (2010) aponta que nos próximos dez anos os modelos sociais pós-industriais da web irão ser materializados no mundo dos átomos, ou seja, essa realidade está mais próxima do que poderíamos imaginar. Sendo assim o ambiente virtual (web) torna-se a ferramenta ideal para obter um design exclusivo.

Para essa nova realidade, as empresas buscam novas saídas envolvendo a comunidade em seus projetos, como o modelo de crowdsourcing. Nesse modelo os profissionais são responsáveis pela parte técnica e a sociedade é responsável em dar forma e estilo ao produto. Esse modelo de produção permite preencher as lacunas existentes entre a concorrência das grandes fábricas.

Anderson (2010) afirma que a fabricação digital possibilita gerar um novo modelo produtivo que traz transformações semelhantes à introdução dos computadores pessoais e à internet na vida contemporânea, mudanças representativas aos meios de produção principalmente em relação a flexibilidade, trabalho em rede, mobilidade e acesso individual e comunitário (ANDERSON, 2010). Quando modelos tão familiares ao universo virtual invadem o mundo real trazem consequências positivas como a quebra de paradigmas, por exemplo, da necessidade de uma estrutura física para ser uma grande empresa, hoje é possível conectar através da internet: profissionais, estudantes e curiosos de qualquer parte do mundo para desenvolver qualquer produto.

Para atender a demanda da comunidade que se forma a partir desses novos modelos, como os makersque saem das suas "garagens", surgem espaços propícios à experimentação e que proporciona contato com outros entusiastas. Algunsdesses espaços são os: Hackespaces, TechShops, 100K Garagens e FabLabs (GHALIM, 2013).

Os espaços como os 100k Garages disponibilizam sua infraestrutura para a reprodução de projetos; já os Tech Shops fornecem a infraestrutura como: ferramentas, equipamentos e maquinário eauxiliam no desenvolvimento dos projetos; os Hackerspacese Fablabs são espaços mais comprometidos com o desenvolvimento de projetos e da comunidade, também disponibilizam a infraestrutura, porém os FabLabs não são espaços prestadores de serviços para a reprodução de projetos. Para Troxler (2013) o FabLab além de possuir os equipamentos e suprir necessidades técnicas, é uma rede social que conecta lateralmente seus usuários, pois nesse contexto a fabricação digital rompe com os sistemas hierárquicos e promove sistemas mais horizontais de produção (TROXLER, 2013).

\subsection{Colaboração e trabalho em rede}

Junto com o surgimento dos laboratórios de fabricação digital, e com base nos princípiosda troca de experiências e da colaboração, aparecem novas formas de co- 
criação em design. Alguns dos conceitos que apareceram na pesquisa incluem o peerto-peer, co-design, open (open source, open design e openinovation). Tais formas de criação e produção trazem a tona uma nova forma de fazer design que impacta diretamente na metodologia e nas ferramentas utilizadas nos processos de design tradicional.

O Peer-to-peeré um sistema auto-organizável de pares iguais e autônomos que aponta para o uso compartilhado de recursos distribuídos em um ambiente de rede.Este mecanismo pode ser utilizado para qualquer tipo de recursos distribuídos e deve oferecer novas possibilidades para aplicações na internet

Já o conceitoOpen é uma característica central para plataformas que tem por objetivo transmitir e reforçar a partilha, reciprocidade, colaboração, tolerância, igualdade, justiça e liberdade (AVITAL, 2011). Segundo o autor, esse conceito pode ser classificado em três formatos Open source(Código aberto), Open Innovatione Open design.

Open source: Tem como proposta de valor enfatizar as capacidades relacionadas com a abertura, modificação e desenvolvimento colaborativo. Os atores principais do open sourcesão os desenvolvedores de softwares. O formato open sourcetem se tornado cada vez mais familiar inclusive a pessoas que não tem afinidade nenhuma com programação e tecnologia da computação.

Open innovation: A proposta de valor é impulsionar a inovação de forma aberta, distribuindo processos e conhecimentos. Seus atores principaissão as organizações. No modelo Open innovationos líderes das indústrias buscam fazer o melhor uso das ideias internas e externas para desenvolver modelos de negócios que favoreçam a troca de conhecimento, a propriedade intelectual e comércio. Essa troca com o ambiente tanto externo como interno estende as capacidades inovadoras de uma empresa. Os princípios da inovação aberta têm promovido a proliferação de comunidades de práticae lançou as bases de crowdsourcing(AVITAL, 2011).

Open design: A principal característica é a fabricação colaborativa através de processos que enfatizam as capacidades relacionadas com o uso do conceito Open. Embora os designers desempenhem um papel fundamental produzindo e compartilhando projetos de design, os atores principais de Open design são os consumidores finais (AVITAL, 2011).

O Open design oferece possibilidades inéditas para o design e no desenvolvimento de projetos da mesma forma para profissionais e como amadores. Considerando que o modelo industrial mantém o foco da produção para a criação de produtos destinados às massas, a era digital (fabricação digital e Open) cria um ambiente oportuno para que a própria massa projete, fabrique e comercialize seus produtos com as características necessárias para atender sua realidade. Deste modo o modelo tradicional que é formado verticalmente pelas relações: projetista - fabricante - distribuidor - consumidor e o modelo de design aberto se diferenciam porque este oferece alternativa aberta de ligação direta entre designers e consumidores. Estas relações estendidas, transitórias e não hierárquicas criam matrizes dinâmicas e flexíveis que não são apenas centradas no usuário, mas orientado para o usuário. (AVITAL, 2011). O quadro 1 resume os arquétipos do Open-x. 
Quadro 1 - Arquétipos do Open-X.

\begin{tabular}{|l|l|l|l|}
\hline & Open Innovation & Open Source & Open Design \\
\hline Proposta de Valor & Conhecimento Distribuído & Desenvolvimento Distribuído & Fabricação Distribuída \\
\hline $\begin{array}{l}\text { Caraterística } \\
\text { Principal }\end{array}$ & Visualização & Modificação & Uso \\
\hline Atores Principais & Organizações & Comunidades & Usuários Finais \\
\hline
\end{tabular}

Fonte: Avital, 2011 (adaptação do autor).

Diversos tipos de projetos podem ser materializados em espaços FabLab, passando pelas mais diferentes áreas do conhecimento. No próximo tópico serão apresentadas diversas iniciativas de design de moda produzidas dentro do contexto da fabricação digital. Serão também apresentados diversos depoimentos de profissionais que atuam nesse novo campo, evidenciando as possibilidades da fabricação digital associada à moda.

\section{MODA E FABRICAÇÃO DIGITAL NA PRÁTICA}

Considerando o caráter vanguardista de lançar tendências e movimentar grandes setores da economia, o design de moda começa a explorar e até certo ponto a usufruir das possibilidades da fabricação digital. A seguir, são apresentados alguns projetos pioneiros e possibilidades de uso dessa tecnologia para a criação, produção e comercialização de produtos de moda.

A utilização dos processos de fabricação digital são bastante recente no universo do design de moda. Entre os pioneiros da moda encontramos a designer holandesa Iris Van Herpen uma das primeiras designers a desfilar na Semana da Altacostura de Paris, em 2011, com a coleção intitulada Capriole (figura 1). Nessa ocasião, todas as peças apresentadas foram desenvolvidas através da fabricação digital, utilizando a impressora 3D para sua confecção.
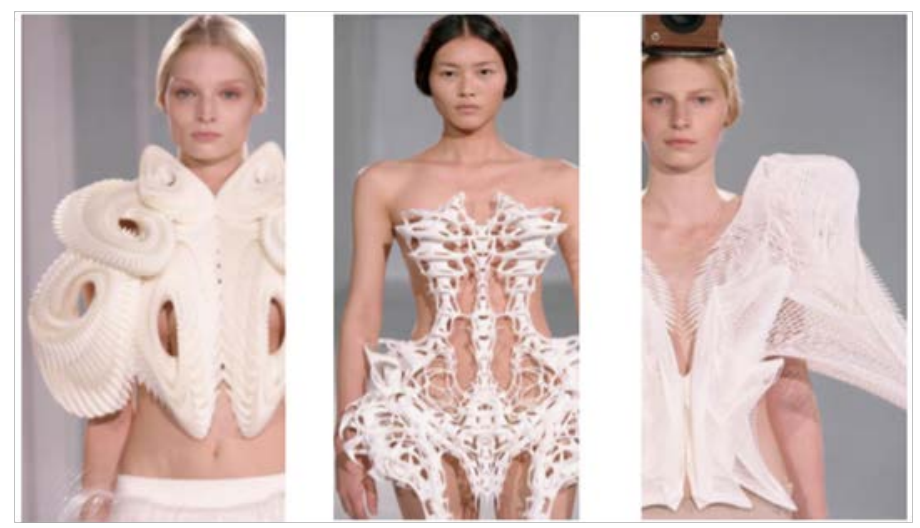

Figura 1 - Coleção Capriole de Iris Van Harpen.

Fonte: HARPEN,Iris Van (site).

A designer alemã Anna Wilhelmi também desenvolveu uma coleção inspirada no futebol americano utilizando a impressora 3D que foi apresentada no evento Samsung Galaxy Fashion Force(figura 2).

Nesse projeto, além da impressão de peças, foi realizado o processo de digitalização utilizando um scanner 3D onde os dados foram compilados e editados 
para criar o estilo que o artista imaginou. Para a impressão em 3D foi utilizado o processo de sinterização a laser que levou em torno de cinco dias para conclusão de todas as pecas da coleção.
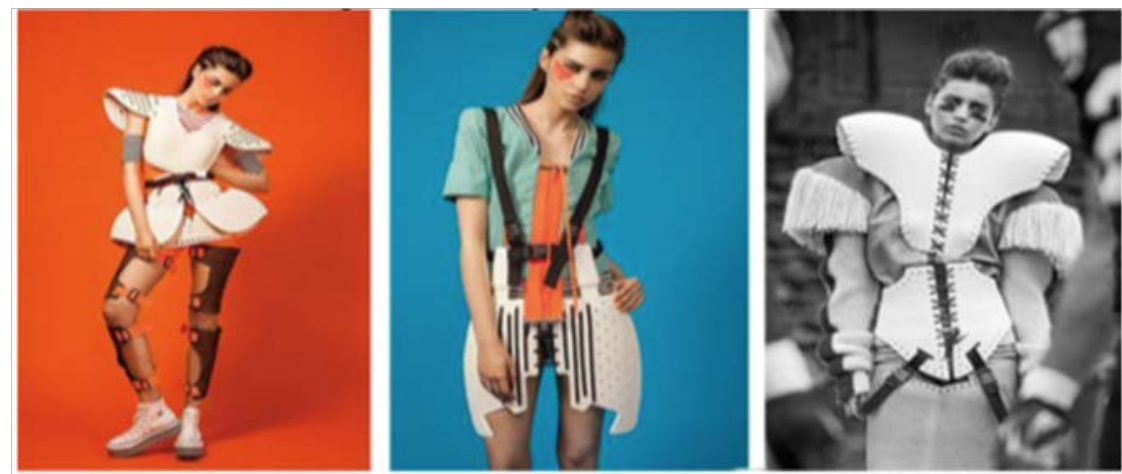

Figura 2 - Coleção Futebol Americano de Anna Wilhelm.

Fonte: WIHELM, Anna (3D PrintingIndustry).

O biquíni N12 é um projeto do escritório de design Continuum. Todas as partes da peça são impressas em 3D, incluindo o fecho. As partes se encaixam sem precisar de nenhum tipo de costura (figura 3). O nome da peça N12 é devido ao material que é utilizado - Nylon 12. Este é um nylon sólido que permite dobrar sem quebrar mesmo que a impressão seja muito fina.

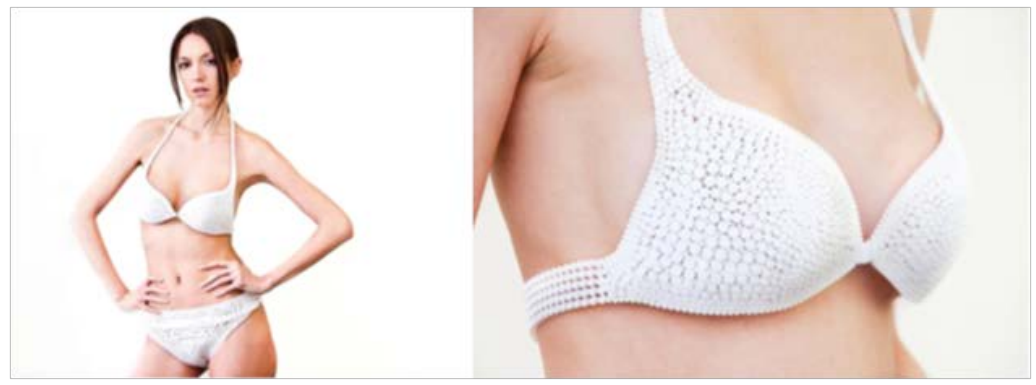

Figura 3 - Bikini N 12.

Fonte: CONTINUUM (Site).

O designer Coreano EunsukHur utiliza o corte a laser para criar multicamadas, gravuras e impressão em têxteis (figura 4). Motivado pela forma que as plantas e animais se adaptam ao ambiente em que crescem, ele projeta peças que envolvem o usuário e são capazes de se ajustar a forma do usuário.

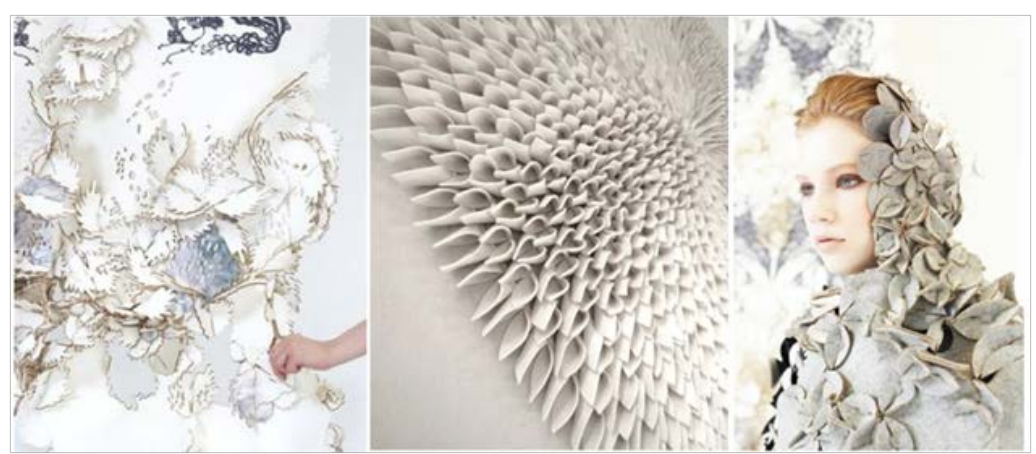

Figura 4 - Peças cortadas a laser do designer EunsukHur. Fonte: HUR, Eunsuk(Site) 
A designer alemã Elisa Strozyk cria composições e estampas combinando madeira e padrões geométricos criando texturas que ela chama de "WoodenTextiles" (madeira têxtil). Através do corte a laser de pedaços de madeira que são aplicados a uma base de tecido, é possível criar o efeito tridimensional, mesclando a rigidez com a flexibilidade (figura 5).

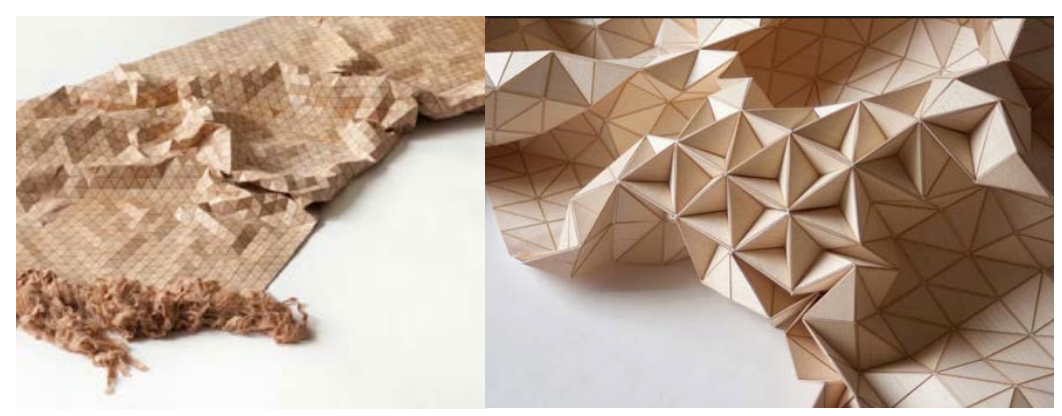

Figura 5 - WodenTextiles da designer Elisa Strozyk

Fonte: STROZYK, Elisa (Site).

Os wearables (vestíveis) são caracterizados pela integração de sistemas e componentes eletrônicos a produtos têxteis. Devido a sua versatilidade existem diversas possibilidades de aplicações, um exemplo são produtos voltados para a área de saúde. Muitos designers de moda também utilizam esta tecnologia com propósitos estéticos, de interação ou simplesmente diversão, como o projeto da estilista Ying Gao que criou dois vestidos que se contorcem e acendem quando uma pessoa olha para eles (figura 6). Utilizando o sistema de rastreamento ocular (eyetracking), para que os vestidos sejam ativados com o olhar do espectador, o sistema ativa pequenos motores que ativam o movimento dos vestidos. Os vestidos são confeccionados em organza, com fios fotoluminescentes que se movimentam com o pregueado do tecido e dos componentes eletrônicos.

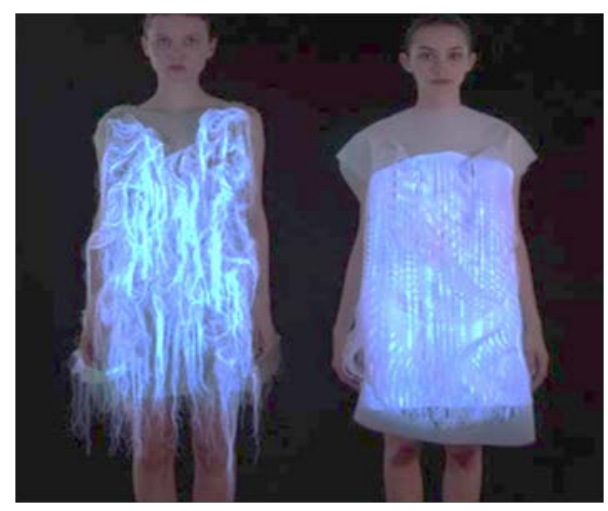

Figura 6 - Vestidos (no)where (now)here. Fonte: GAO, Ying (Site).

\subsection{Visão dos designers em relação à fabricação digital}

Com o intuito de mapear as iniciativas de moda no contexto da fabricação digital na rede FabLab, foram conduzidas uma série de entrevistas semiestruturadas com designers de moda atuantes na rede FabLab. Os projetos desenvolvidos pelos 
entrevistados permeiam todo o processo produtivo da cadeia da moda vão da construção de uma máquina de tecelagem, passando pelo desenvolvimento de materiais têxteis e o desenvolvimento de produtos de moda. A amostragem para o contexto fabricação digital partiu da indicação feita por participantes da rede Fab Lab. Foram selecionados os entrevistados que desenvolveram projetos que envolvessem fabricação digital e moda, em diferentes países, de diversos seguimentos como: têxteis, maquinários open source, acessórios e vestuário.

\subsection{Perfil dos Entrevistados}

Emily Sato após vivenciar a experiência no FabLab de Manchester vislumbrou a oportunidade de trabalhar com a fabricação digital de "joias" (como ela chama). Os acessórios são projetados digitalmente para uma empresa que os produz e comercializa através do site (figura 7). No site é possível escolher o tamanho da peça e as cores. Com uma sócia criaram a instituição Fashnology que tem como proposta promover atividades e workshops combinando moda e tecnologia na proposta dos weareables (vestíveis), fabricação digital e processo tradicional.

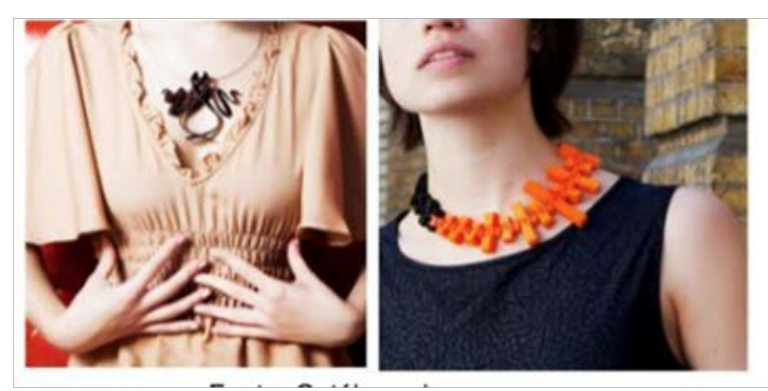

Figura 7 - Acessórios Emily Sato.

Fonte: WONDERLUK (Site).

Gerard Rubiodesenvolveu o OpenKnit uma máquina de tecelagem open source e de baixo custo, calcula que custa menos de $550 €$ (figura 8). O usuário é capaz de produzir suas próprias roupas a partir de arquivos digitais, com o objetivo de permitir que 0 usuário tome suas próprias decisões usando a criatividade.
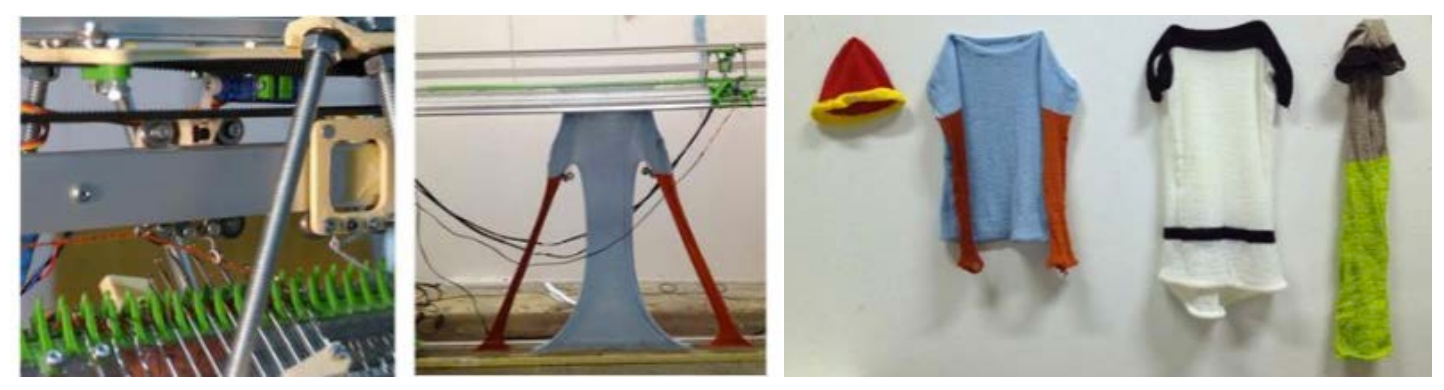

Figura 8 - Open Knit.

Fonte: OPEN KNIT (Site).

AnastasiaPistofidou coordena o FabTextile (do FabLab Barcelona). Laboratório que parte das possibilidades da fabricação digital e necessidade de experimentar os conhecimentos da fabricação em outros campos da indústria têxtil. Pistofidou está envolvida com os projetos que são desenvolvidos noFabTextile, como por exemplo: Fridge Bag: projeto que utiliza LEDs, embutidos no tecido, que se acendem quando 
alguém abre a bolsa para encontrar suas coisas (figura 9). A bolsa, feita de tecido e silicone, tevea base desenvolvida a partir de um molde 3D fabricado em uma fresadora. Modularidad: é um projeto têxtil, com o objetivo de criar uma estrutura modular a partir da fabricação digital. As peças modulares são de feltro cortado a laser, além disso, possuem um sistema de circuitos para a introdução de iluminação LED. Bordado digital em bolsas: foi desenvolvido utilizando a bordadeira digital, uma das máquinas do Fab Lab. Com ela é possível bordar sobre qualquer material têxtil a partir de desenhos desenvolvidos em software de vetor, neste projeto foi utilizado o Illustrator, a bordadeira digital é capaz de ler os campos de cor, aplicando a cor desejada ao bordado escolhido.
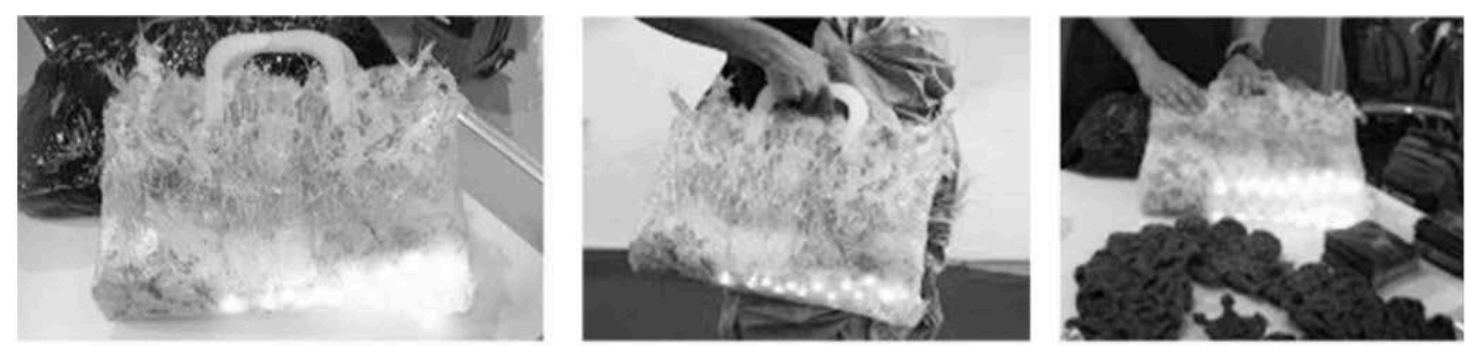

Figura 9 - Fridge Bag.

Fonte:FAB TEXTILES BARCELONA(Site).

Josiane Belina-Contaux produz artigos em couro reciclado por encomenda, como bolsas, carteiras, chaveiros e caderninhos. Utiliza a cortadora laser para fazer cortes e personalizar de acordo com a escolha do cliente. Além dos artigos em couro a Josiane participou do projeto colaborativo Bicloone no FabLabGennevilliers, na França. O conceito do projeto era propor uma jaqueta para ciclistas que fosse elegante e possuísse setas direcionais para indicar aos motoristas sua direção (figura 10).

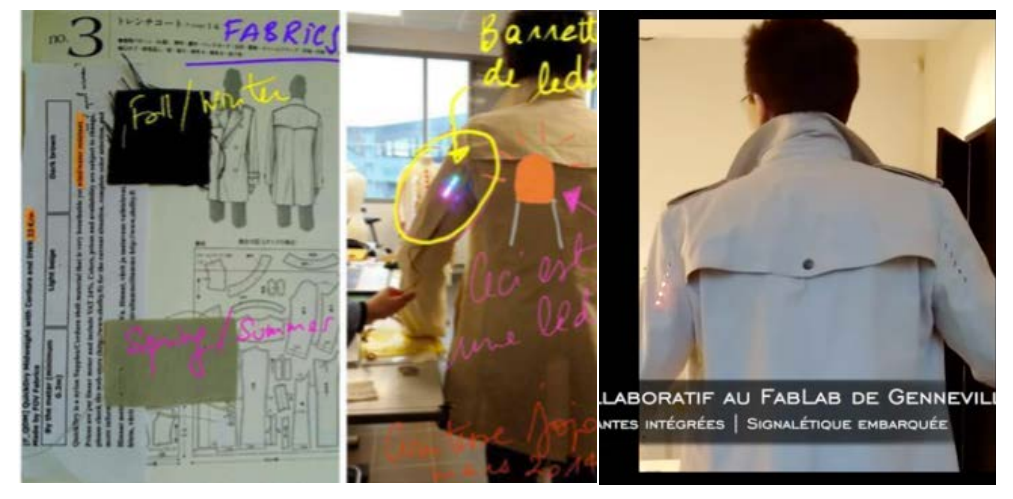

Figura 10 - Bicloone.

Fonte: BICLOONE (Site)

\subsection{Moda e fabricação digital na visão dos entrevistados}

Uma das primeiras ideias apontadas pelos entrevistados do Contexto Fabricação Digital é que a prototipagem faz parte da etapa de experimentação do processo de design. Se relacionarmos o processo de fabricação digita com as metodologias tradicionais de design,veremos que a prototipagem acontece geralmente na Fase de Geração de Ideias. Nesta fase são definidos apenas parâmetros para o projeto, que podem partir de um briefing (pré-definido), por uma necessidade, 
ou do próprio produto. Segundo os entrevistados, o objetivo é permitir que a experimentação gere alternativas e não necessariamente se tenha controle total do resultado final. Nesse sentido, a prototipagem colabora para a criação e configuração final do produto e o processo de experimentação pode estar relacionado a aspectos técnicos, tecnológicos, de materiais, de processos e de open design quando o objetivo é trabalhar com algum projeto disponibilizado.

A falta de conhecimento técnico e/ou tecnológico a respeito da fabricação digital (uso dos equipamentos ou softwares) foi outro dos itens ressaltado pelos entrevistados. Segundo eles, surgem dificuldades por conta das limitações dos próprios equipamentos assim como dos materiais existentes. Estas afirmações levantam algumas questões a respeito do tema, sobre se esta falta de conhecimento ou preparo se deve por estarmos lidando com uma tecnologia relativamente nova em que as pessoas não tem acesso, ou ainda a falta de capacitação e formação que possibilite o uso dessa tecnologia dentro dos cursos de design e moda, dentre outras questões referentes ao campo do conhecimento e ensino, nos cabe então refletir sobre o assunto.

Outro aspecto que chama a atenção é o fato de que nenhum dos entrevistados possui formação acadêmica em design de produtos ou moda. Todos eles são formados em áreas afins como arquitetura e design gráfico ou ainda administração. Esse fato reforça a ideia de Rittel (1987) de que o design não é apenas propriedade dos designers. $\mathrm{O}$ autor entende que qualquer pessoa ou profissional com capacidade de planejar pode gerar um produto de design.

Curiosamente, três dos quatro entrevistados tiveram o primeiro contato com a fabricação digital nos cursos onde se formaram. 0 interesse em desenvolver projetos relacionados a moda utilizando a fabricação digital, em algum nível do processo, surgiu na maioria do casos por consequência de alguma outra atividade desenvolvida, o que os levou a identificar a oportunidade de suprir uma demanda existente para a área de moda. Além disso, os entrevistados ressaltaram a falta de cursos e atividades de formação voltada para a área de moda, o que resultou como oportunidade por dois dos entrevistados que hoje desenvolvem atividades acadêmicas relacionadas com a pesquisa de materiais voltados para produtos de moda.

Essa realidade se reflete nos cursos técnicos, tecnólogos e de graduação ofertados no contexto brasileiro. Observando as matrizes curriculares da maioria dos cursos de design de moda, é possível perceber a ausência de unidades curriculares que contemplem atividades experimentais e de fabricação digital.

Numa análise dos currículos de oito cursos de design de moda observa-se que as unidades curriculares que talvez se aproximem da proposta de fabricação digital são as disciplinas de Tecnologia Têxtil, Tecnologia da Confeç̧ão, Modelagem computadorizada, Materiais tecnológicos aplicados à moda entre outras. Numa análise mais detalhada das ementas desse cursos, podemos observar que as matrizes curriculares e métodos tradicionais para o desenvolvimento de produtos de moda, estão voltadas para atender as demandas dos processos de produção industrial, e não trabalham ainda com os paradigmas da fabricação digital.

De toda forma a falta de conhecimento específico não tem sido empecilho para o uso da fabricação digital, inclusive este é um dos conceitos centrais que estamos abordando nesta pesquisa, democratizar e desmistificar a tecnologia. Neste ponto os entrevistados estão divididos, dois afirmaram ter experiência prática e domínio da 
tecnologia de fabricação digital, já os outros dois assumiram ter dificuldades com o uso de softwares e/ou equipamentos da fabricação digital e precisaram solicitar ajuda a outras pessoas ou recorrer aos FabLabs para conseguir desenvolver o projeto. Assim fica claro que a falta de domínio não impede o desenvolvimento dos projetos.

É evidente que por vezes estudantes ou profissionais da área de moda possam encontrar dificuldades no primeiro contato com a fabricação digital, talvez por causa dos softwares utilizados para a fabricação digital não serem comuns ao cotidiano da atividade na área de moda.

Considerando que o FabLab é um espaço propício para a experimentação, troca de conhecimento e resolução de problemas locais, possibilitando a utilização dos equipamentos e ferramentas de fabricação digital, todos os entrevistados em algum momento do desenvolvimento de seus projetos contaram com o apoio de algum FabLab da rede, principalmente os dois que admitiram ter dificuldades com o uso da tecnologia. Ainda um dos entrevistados tem a oportunidade de desenvolver pesquisas de materiais têxteis por estar inserido no Fab Lab.

Foi feito um questionamento a respeito do que os entrevistados imaginam de espaços alternativos, a exemplo do FabLab, para o desenvolvimento de produtos de moda. De acordo com os entrevistados, o FabLab é um mecanismo e espaço físico propício para a criação, inovação e desenvolvimento de ideias principalmente pela possibilidade de materializá-las. Mais da metade dos especialistas ressaltaram a importância do contato com a comunidade, que está disponível para colaborar com a realização dos projetos, compartilhar conhecimento e informações.

Outra questão levantada foi a necessidade de descentralização da produção em massa permitindo que as pessoas entendam como as coisas funcionam, conheçam todo o processo de produção e se envolvam com ele, desta forma é possível criar produtos com outros valores e atribuir novos significados a eles.

\section{CONCLUSÃO}

O FabLab conta com uma infraestrutura composta por diversos equipamentos e ferramentas que permitem a qualquer pessoa utilizando a fabricação digital materializar suas ideias. Talvez a falta de conhecimento dos profissionais, estudantes ou pessoas interessadas na área de moda a respeito dessa infraestrutura e as possibilidades que o maquinário permite, reflita no volume de projetos desenvolvidos nos FabLabs quando comparados a projetos de outras áreas.

Podemos confirmar isto a partir do mapeamento dos projetos desenvolvidos na rede FabLab, pois dos 267 FabLabs mapeados apenas 16\% dos FabLabs em operação desenvolveram projetos relacionados com o universo da moda, sendo Holanda e França os países que mais desenvolveram projetos. O mapeamento foi realizado através das informações disponibilizadas nos sites dos próprios FabLabs, partindo do princípio de que para fazer parte da rede é necessário disponibilizar as informações e projetos através dos sites. Entende-se que aqueles Fablabs que de alguma forma desenvolveram projetos na área disponibilizam essas informações.

É perceptível que o maquinário disponível em espaços como o FabLab permite uma grande diversidade de uso, desconhecida pela maioria dos profissionais hoje atuantes. Entendesse que o FabLab não se propõe a substituir o processo de desenvolvimento e produção de produtos de moda tradicional ou industrial, mas propõe novas alternativas para processos conhecidos e novos efeitos para materiais, 
texturas, forma, estruturas novas que alimentam a criatividade. Através da fabricação digital é possível desenvolver estruturas impossíveis de serem calculadas pelo ser humano, projetos como da designer Iris Van Herpen são exemplo disto.

Desta forma é importante que sejam desenvolvidas ações de sensibilização, principalmente na indústria visto que uma grande parte dos entrevistados não visualiza as possibilidades da fabricação digital no desenvolvimento de suas atividades.Ao contrário dos profissionais que atuam em ateliê, que desconhecendo a maioria dos equipamentos, demonstraram interesse em conhecer a aplicação da fabricação digital.

Em consequência do desconhecimento da maioria dos profissionais e a preocupação de como essa tecnologia pode influenciar o processo de desenvolvimento e o produto em si, outra questão é levantada através da pesquisa, de como atribuir significados a este novo modelo de fabricação, assim como aos métodos e processos, além dos produtos resultantes desta atividade. É importante que a comunidade se aproprie da fabricação digital e atribua a ela significados como objetivo de reconhecer as potencialidades e conseguir explorar ao máximo as possibilidades, questões estas que estão diretamente relacionadas com as questões culturais e educacionais.

\section{REFERÊNCIAS}

ANDERSON, Chris. Átomos são os novos Bits. Revista Exame, 2010. Disponível em: < http://exame.abril.com.br/revista-exame/noticias/atomos-sao-novos-bits-533969>. Acesso em: 04 set. 2015.

AVITAL, Michel. Open Design Now: The GenerativeBedrock Open Design, Amsterdam: Bis publishers, 2011. Disponível em:

$<$ http://opendesignnow.org/index.php/article/the-generative-bedrock-of-opendesign-michel-avital/\#fn-405-1>. Acesso em: 14 nov. 2015.

BICLOONE. Projeto Bicloone (Figura 10).Disponível em: <http://www.faclab.org/wpcontent/uploads/bicloone-report.pdf> Acesso em: 12 ago. 2016.

CONTINNUM.Biquíni N12(Figura 3). Disponível em:

<http://continuumfashion.com/N12.php> Acesso em: 12 ago.2016

FAB TEXTILES BARCELONA.FRIDGE BAG (FIGURA 9). Disponível em: <https://fabtextiles.org/> Acesso em: 12 ago. 2016

GAO, Ying.Vestidos (no)where (now)here (Figura 6). Disponível em: <http://yinggao.ca/> Acesso em: 12 ago. 2016

GERSHENFELD, Neil. Fab: The ComingRevolutiononYour Desktop. New York: Basic Books, 2005.

GERSHENFELD, Neil. HowtoMakeAlmostAnything The Digital FabricationRevolution. EUA: ForeignAffairs, 2012.

GHALIM, Aurelie. FabbingPractices: Na Ethnography in FabLab Amsterdam. 2013. Dissertação (Mestrado) - Universiteite Van Amsterdam, Master of Media andCultureStudies.

HARPEN, Iris Van. Coleção Capriole (Figura 1).Disponível em: <http://www.irisvanherpen.com/> Acesso em: 12 ago. 2016. 
HUR, Eunsuk.Peças cortadas a laser (Figura 4) Disponível em:

<http://www.eunsukhur.com/> Acesso em: 12 ago.2016

MAKERS. The New Industrial Revolution. New York: Crown PublishingGroup, 2012.

OPEN KINIT. Projeto Open Kinit (Figura 8).Disponível em: <http://openknit.org/>

Acesso em: 12 ago. 2016

RITTEL, Hortst W.J. The Reasoningof Designers. Apresentado em: paper zum

InternationalCongresson Planning and Design Theory in Boston, Ago. 1987.

STROZYK, Elisa.WodenTextiles (Figura 5). Disponível em:

<http://www.elisastrozyk.de/> Acesso em: 12 ago. 2016

THACKARA, John. Open Design Now: Intothe Open. Amsterdam: Bis publishers, 2011.

TROXLER, Peter. Makingthe 3rd Industrial Revolution. The Struggle for

PolycentricStructuresand a New PeerProductionCommonsin theFabLabCommunity, Apresentado em: J. Walter-Herrmann \& C. Büching (Eds.), 2013.

WILHELM, Anna. Coleção Futebol Americano (Figura 2), 3D PrintingIndustry.

Disponível em: <https://3dprintingindustry.com/news/3d-printing-new-fashion-

collection-25084/> Acesso em: 12 ago. 2016

WONDERLUK. Acessórios de Emily Sato (Figura 7). Disponível em:

<http://wonderluk.com/collections/emily-sato> Acesso em: 12 ago. 2016. 